\title{
Online Creative Learning Model: Effective Asynchronous Integration
}

\author{
Michael Pickett \\ National University
}

This paper extends previous research that developed an online creative learning model from which educators are able to seamlessly integrate assessment techniques into overall curriculum development. With the current course content delivery modality reliability issues plaguing many universities, it is imperative that we, as educators, understand our critical roles. A fundamental argument in asynchronous learning is the dichotomy between constructivism and objectivism and overall student experience. This paper provides a theoretical model by which the curriculum development process and instructor can maximize engagement and enrich the students' asynchronous online educational experience.

\section{INTRODUCTION}

In higher education, much focus has been placed on the adult leaner and their specific learning styles in non-traditional modalities and pedagogies (Pickett, 2008), however, that school of thought may not fully apply to the asynchronous environment. In today's environment the asynchronous modality is gaining popularity but without some type of instructor/content videos, students feel distant from the instructor (Han, 2013). Similarly, according to Niess and Gillow-Wiles (2013), utilizing only a “...textbased, asynchronous discussion forum as the primary communication...is limited" (p. 9). It is therefore critical that the instructor maximizes student engagement through frequent communication and active participation in the course discussion boards and maximizes participation in any other interactive activities with the students.

Andersen (2009), argued two major components of a successful asynchronous discussion. The first is the role of the instructor. The role of the instructor changes dramatically due to the loss of face-to-face time during the class. In as much as discussion forums are typically "pre-canned", the instructor needs to actively contribute to keep a coherent and collaborative discussion thereby encouraging students to become more "cognitively involved". Such an example would be to ask the student "what to do" rather than "what they thought" of a situation. Reframing discussions in this way also contributes to increased critical thinking skills. The second component of a successful asynchronous discussion is to achieve deeper and higher order learning. Andersen (2009) found that students with increased quality participation in discussion boards demonstrated higher levels of cognitive engagement versus students with less knowledge construction in their discussion interactions.

Lastly, there is much discussion about the efficacy of instructors in the asynchronous environment. It bears reminding that the asynchronous environment is only another modality of instruction. The "precanned" appearance of the courses does not preclude instructors from fully engaging students throughout the course in many ways. As the asynchronous modality matures it will become more evident to many 
that there is, in actuality, more work for instructors than with a traditional synchronous online or face-toface course. As we all face the challenges of creating a highly engaging learning environments and increasing our communication skills in varying ways, best practices will soon evolve to help guide the future of the asynchronous modality.

\section{REVIEW OF THE LITERATURE}

This paper further explores the integration of the learner-centered assessment model (L-CAM) and the Online Creative Learning Model (Pickett, 2015) as they apply to the development of asynchronous courses. By integrating the various processes in curriculum design methodology and developing assessment methods within the process, we can mitigate the assessment challenges that arise when we develop asynchronous courses. This model affords educators an opportunity to focus on learners as the center of the assessment process and provides a systemic approach to espousing our institutional values with the needs of our learners and communities (Figure 1).

\section{FIGURE 1}

\section{LEARNER-CENTERED ASSESSMENT MODEL (L-CAM)}

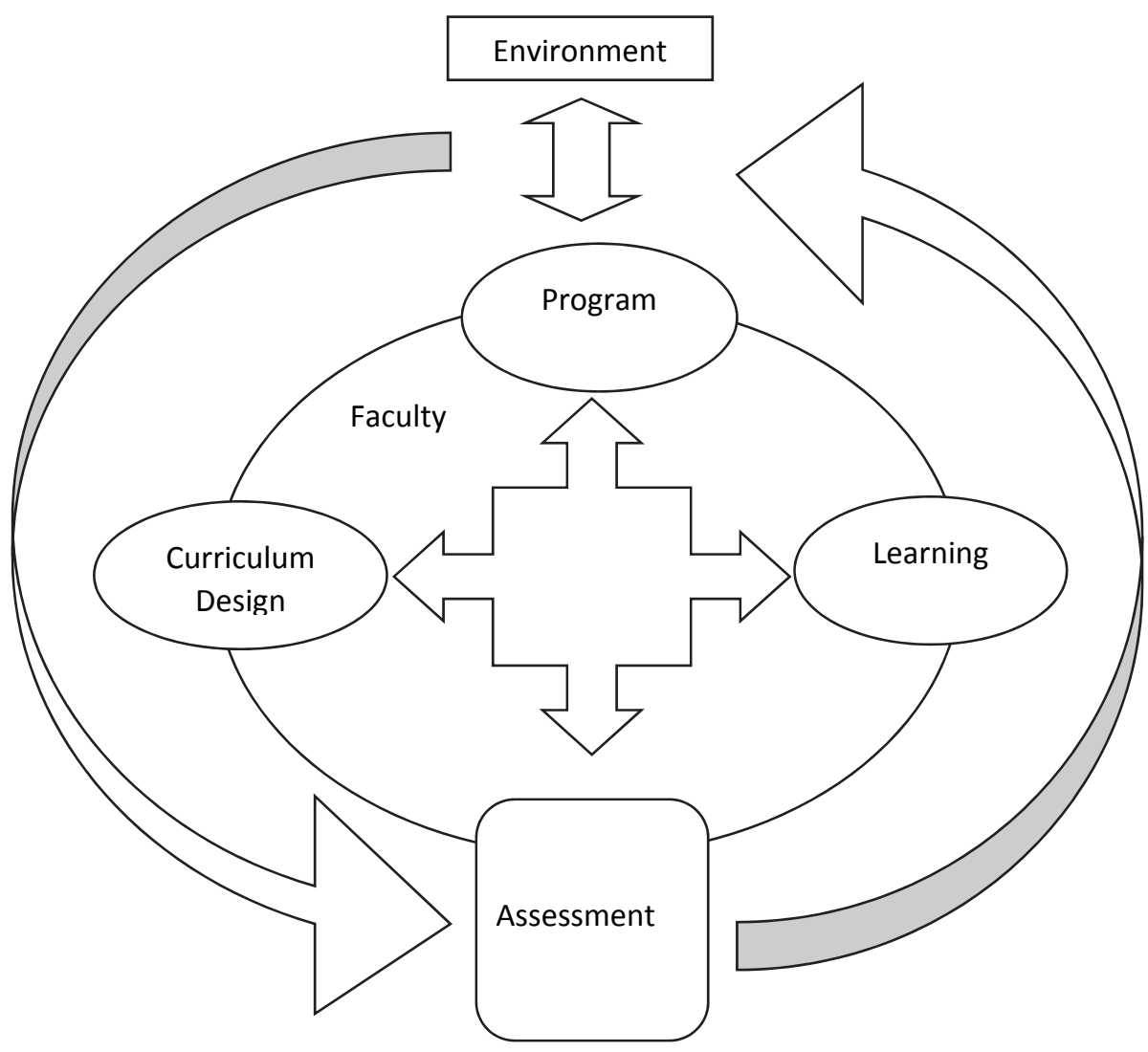

Learner outcomes define student expectations as well as the alignment of the curriculum as it is applied in the classroom. The understanding of how our curriculum design "fits" into our overall assessment process is a critical aspect in the assimilation of a learning organizational view (Lin \& Hwa, 2002). Sipos, Battisti, and Grimm (2008) argue for the adaptability of multiple domains of learning into the learning context through a transformative process. Additionally, Sipos, Battisti, and Grimm (2008) 
found that learning outcomes ideally would create a synergy between the varying aspects of the learning context i.e., critical thinking, reflection, and engagement.

\section{Structural Activities in Curriculum Development}

Clarke et al. (2006) provided a process, or model for developing curriculum that contained the following set of structural activities:

1. Beliefs about the content area

2. The major themes of the content area

3. Identification of the general focus and direction that students will be guided

4. Mastery skills and concepts required, and

5. The pedagogical methods that achieve desired course outcomes.

When the components of the L-CAM model (Figure 1) are aligned to Clarke's structural activities we are better able to visualize the many relationships (Table 1).

\section{TABLE 1}

\section{L-CAM COMPONENTS AND STRUCTURAL ACTIVITIES RELATIONSHIPS}

\begin{tabular}{|c|c|c|}
\hline L-CAM Components & \multirow{6}{*}{ 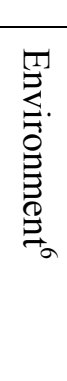 } & Structural Activities \\
\hline Faculty $^{1} /$ Learner $^{2}$ & & Beliefs about a content area \\
\hline $\begin{array}{l}\text { Program } \\
\text { Outcomes } 3 / \text { Faculty }^{1} / \text { Learner }^{2}\end{array}$ & & The major themes of the content area \\
\hline $\begin{array}{l}\text { Learning } \\
\text { Outcomes } / \text { Faculty }^{1} / \text { Learner }^{2}\end{array}$ & & $\begin{array}{l}\text { Identification of the general focus and } \\
\text { direction that students will be guided }\end{array}$ \\
\hline Assessment $^{4} /$ Faculty $^{1} /$ Learner $^{2}$ & & Mastery skills and concepts required \\
\hline $\begin{array}{l}\text { Curriculum } \\
\text { Design }^{5} / \text { Faculty }^{1} / \text { Learner }^{2}\end{array}$ & & $\begin{array}{l}\text { The pedagogical methods that achieve } \\
\text { desired outcomes }\end{array}$ \\
\hline
\end{tabular}

Additionally, we are able to see that the environment affects all components as well as the structural activities. Hence, the structural activities within an educational environment could be represented as thus:

$\sum_{i=1}^{N} B_{i} T_{i} F_{i} S_{i} P_{i}$

where $B=$ the beliefs about a content area, $T=$ the major themes of the content area, $F=$ the general focus and directions students are guided, $S=$ the mastery skills and concepts requires, and finally, $P=$ the pedagogical methods that achieve the desired outcomes. Once again referring to Table 1, the superscripts 1 through 6 represent the various components of the L-CAM to better represent the L-CAM Model within the structural activities equation, thus:

$\sum_{i=1}^{N} B_{1,2,6} T_{1,2,3,6} F_{1,2,3,6} S_{1,2,4,6} P_{1,2,5,6}$

A cursory view of the second equation helps us realize the complexity of all L-CAM components and structural activities within curriculum. While this remains behind the scenes, given the various perceptions of the expected course outcomes, it is no wonder that as students log in to a course they quickly analyze assignments, due dates, and any additional requirements and settle in with little thought of "thinking out of the box." Paradoxically, if the course structure does not provide an atmosphere allowing for creative tensions, the initial linear impressions the students perceive become the reality. 
Below (Figure 2) is a model demonstrating the integration of creativity and constructivist learning theory into an online adult learner-centered environment (Pickett, 2015).

\section{FIGURE 2}

\section{ONLINE CREATIVE LEARNING MODEL}

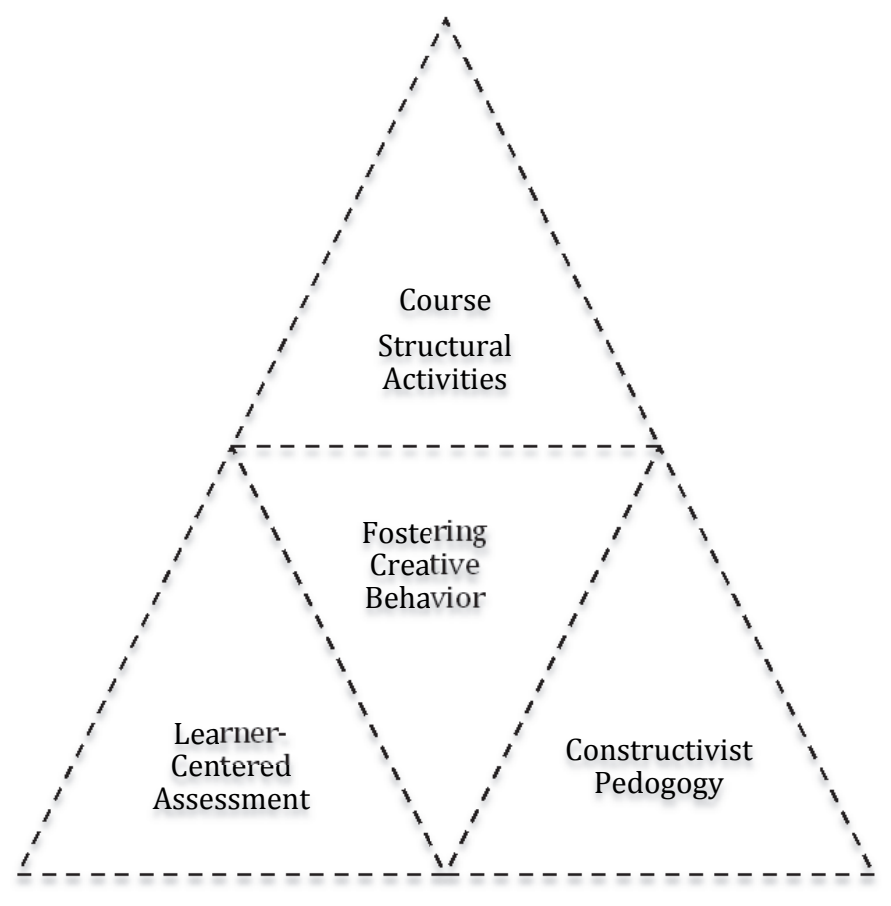

The model integrates the constructs of the L-CAM model and principles of constructivist pedagogy as its foundation. The core of the model houses the principles that we can do as instructors to foster creativity in the classroom environment. Driver (2001, p. 29) identified thirteen steps for the fostering of creative behavior in classrooms:

1. Allowing time for creative thinking

2. Rewarding creative ideas and products

3. Encouraging sensible risks

4. Allowing mistakes

5. Imagining other viewpoints

6. Encouraging explorations of the environment

7. Questioning assumptions

8. Refraining from evaluating/judging

9. Fostering cooperation rather than competition

10. Offering free rather than restricted choices

11. Encouraging dissent and diversity

12. Setting students up for success rather than failure

13. Requiring little if any rote learning.

At the apex of the model are the structural activities that make up our curricular design. The dotted lines throughout the model indicate the notion of free-flowing information between all sections in the form of double-loop learning to include environmental stimuli. For instance, from a systemic perspective in the example of a typical online course, there are schemas from which students experience in the form of expectations. Once formed, these schemas regulate behavior and would continue (single-loop learning). On the other hand, when students change behaviors and adapt to changing systems and sub- 
systems, lasting change occurs (double-loop learning). From a student's experience, they modify their behavior to become resilient to change - a prerequisite in fostering creativity!

\section{Asynchronous Learning}

Distance learning is becoming increasingly commonplace in higher education. According to Watts (2016), synchronous interaction played a larger role in the past but there are increasing studies demonstrating asynchronous popularity. Additionally, Watts (2016) argued that course outcomes, final grades, and project grades showed no significant differences between synchronous and asynchronous delivery formats therefore, instructors need to be keenly aware of their student's individual educational needs.

Peters, Shmerling and Karren (2011) found that while asynchronous learning environments have become a popular alternative-learning model, there are still several mixed feelings surrounding this type of educational delivery model. However, they did find that proactive behavior in female students is significantly related to engagement as opposed to male students based on individual learning style preferences. According to Peters, Shmerling and Karren (2011), in asynchronous courses student engagement is evaluated through discussion boards, so it is even more imperative for instructors to actively participate to ensure a quality learning environment.

In an exploratory factor analysis, Hung and Chou (2014) found three distinctive factors affecting a student's communication-satisfaction in asynchronous courses:

1. Leading communication - includes both upward and downward communication with instructors

2. Communication climate - the degree to which the communication in forums motivates and stimulates students to meet their course goals

3. Horizontal communication - level of students interaction among themselves

Additionally, Hung and Chou (2014) strongly assert that a student's level of communication-satisfaction is strongly correlated to the student's interaction with the instructor.

From a student's perspective, Malik, Fatima, Abid and Sarwar (2017) found significant differences in students' satisfaction levels between synchronous and asynchronous classes. Interestingly, in contrast to Peters, Shmerling and Karren's study (2011) Malik, Fatima, Abid and Sarwar (2017) discovered that males had a greater preference for both synchronous and asynchronous a opposed to female students. In addition, student preferences for synchronous or asynchronous modality varied based on degree program type. For example, BBA students were less satisfied with asynchronous courses as opposed to sociology majors (Malik, Fatima, Abid and Sarwar, 2017).

According to Andersen (2009), the role of the instructor changes significantly in asynchronous courses. In face-to-face or synchronous courses, the contact time experienced by students through tone of voice, expression, and spontaneous discussions are considerably different than forming a discussion forum with a question or topic. In asynchronous courses the instructor's role suddenly becomes intertwined with the students through active participation in the discussion forums to maintain student engagement, participation, and creative discourse.

\section{DISCUSSION}

Asynchronous learning has come a long way over the years, but there are still many problems such as effective communication (Hung \& Chou, 2014; Andersen, 2009) and level of engagement (Peters, Shmerling \& Karren, 2011), which is a cornerstone of the Online Creative Learning Model (Figure 2). The constructivist pedagogy, especially in asynchronous courses is imperative for engagement and success of the student. As curriculum designers we are now able to understand the complexity involved in a development process that not only meets the need of our approval processes, but also provides added value to our learners. In a constructivist course the learners are actively involved in a collaborative environment. Additionally, the activities are interactive, learner-centered, and the instructor facilitates the process of learning and the learners are autonomous and responsible for their learning. 
The second cornerstone of the Online Creative Learning Model (Figure 2) is leaner-centered assessment. This also a major concern among accreditors, for example WASC Accrediting Commission for Senior Colleges and Universities requires assessment in basic core competencies including written and oral communication, quantitative reasoning and information literacy regardless of program of study (WASC, 2013). Current research in asynchronous courses regarding assessment highlights the need for consistent and timely feedback during the course to ensure students are aware of their progress. (Vonderwell, Liang \& Alderman, 2007; Martin, 2009; Niess \& Gillow-Wiles, 2013)

At the heart of the Online Creative Learning Model (Figure 2) is fostering creative behavior. Driver (2001) posited 13 steps for fostering creative behavior and a review of the list clearly illustrates that in an asynchronous class, this clearly impacts the communication and participation requirement of instructors. For example, in synchronous courses, the face-to-face time instructors have with students helps them the feel more engaged in the learning process (Andersen, 2009) which undoubtedly needs to be compensated through more creative and engaging course design and a high-level of participation from instructors since this is the only engagement with instructors students have other than email or scheduled private meetings.

Course structural activities occupy the apex of the Online Creative Learning Model (Figure 2). As curriculum designers we are now able to understand the complexity involved in a development process that not only meets the need of our approval processes, but also provides added value to our learners, who are navigating through an asynchronous course. In addition, a review of Equation (2) reinforces the intricacies and inter-relatedness of program and/or course outcomes, assessment and curriculum design.

Lastly, based on Hung and Chou's (2014) analysis, understanding the critical role increased communication plays in the asynchronous class provides instructors with an awareness that can prevent the isolation many students feel in an instructional setting other than synchronous. Depending on the program of study, the only type of communication instructors have with students other than email are the threaded discussions. The below illustration demonstrates the types of communication for each of the components of the Online Creative Learning Model (Figure 3).

FIGURE 3

\section{ONLINE CREATIVE LEARNING MODEL WITH COMMUNICATION FACTORS}

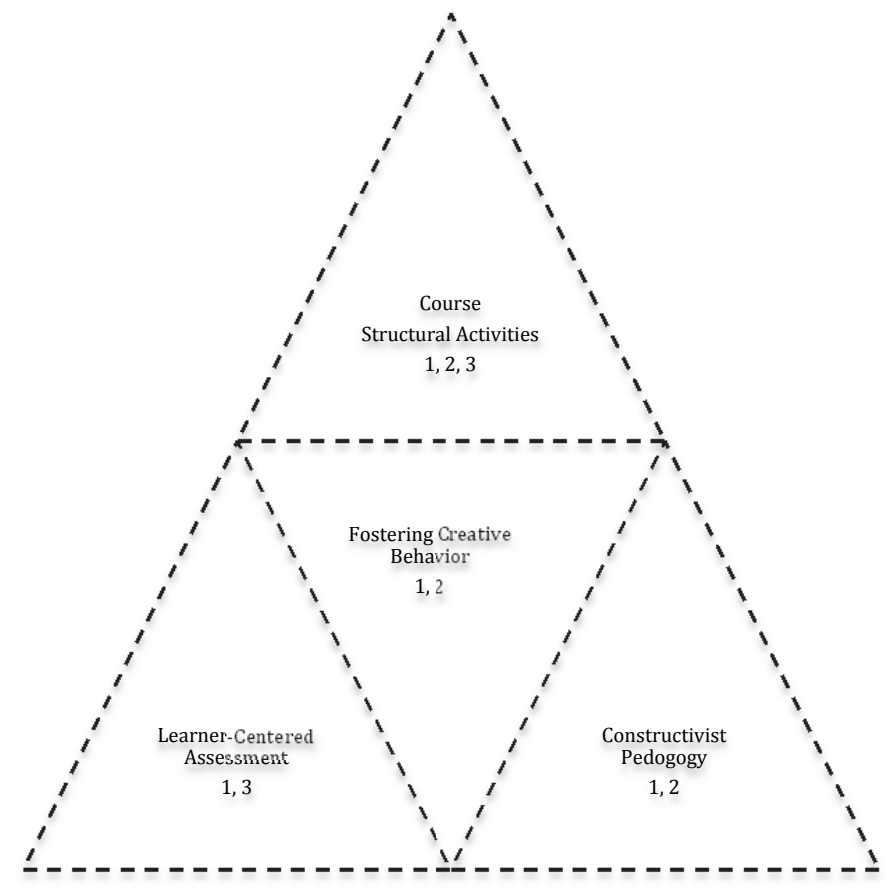


1. Leading

2. Communication Climate

3. Horizontal

Below is a theoretical model (Equation 3) to understand the tremendous impact communication satisfaction $(c s)$ has on the L-CAM Model and structural activities in an asynchronous class. As a reminder, $B=$ the beliefs about a content area, $T=$ the major themes of the content area, $F=$ the general focus and directions students are guided, $S=$ the mastery skills and concepts requires, and finally, $P=$ the pedagogical methods that achieve the desired outcomes. The superscripts 1 through 6 represent the various components of the Learner-Centered Assessment Model (Figure 1; Table 1).

$\sum_{i=1}^{N}\left(B_{1,2,6} T_{1,2,3,6} F_{1,2,3,6} S_{1,2,4,6} P_{1,2,5,6}\right) c S$

As can be observed above, the level of student communication satisfaction affects each parameter of the model thereby demonstrating the critical aspect of student perception of communication satisfaction.

\section{CONCLUSION}

In the asynchronous arena it is not enough that we record and post a lecture with power points with "canned" discussion questions, we, as instructors, need to create an environment that fosters engagement, collaboration, and creative behavior. In an asynchronous course, the discussion board is typically the only communication media instructors have with students other than email. If instructors do not participate fully and engage students in creative discourse, we take the chance of isolating the students and lose the opportunity to maximize their educational experience. As discussed earlier, student satisfaction levels with the asynchronous modality do vary based on student needs and program types. The new instructor role in asynchronous courses aside from that of mentor/facilitator and communicator included active participation in the discussion forums to maintain student engagement, participation, and creative discourse. As shown in the literature, not all students are comfortable with the asynchronous environment. If universities push for a "one size fits all" they will soon find themselves offering programs in modalities that do not fit the needs of many students who then may seek education elsewhere. 


\section{REFERENCES}

Andersen, M. (2009). Asynchronous discussion forums: Success factors, outcomes, assessments, and limitations. Journal of Educational Technology \& Society, 12(1), 249-257.

Clarke, N. Stow, S., Ruebling, C. \& Kayona, F. (2006). Developing standards-based curricula and assessments: Lessons from the field. The Clearing House, 79, 258-261.

Driver, M. (2001). Fostering creativity in business education: Developing creative classroom environments to provide students with critical workplace competencies. Journal of Education for Business, 17(1), 29-33.

Han, H. (2013). Do nonverbal emotional cues matter? Effects of video casting in synchronous virtual classrooms. American Journal of Distance Education, 27(4), 253-264.

Hung, M \& Chou, C. (2014). The development, validity, and reliability of communication satisfaction in an online asynchronous discussion scale. Asia-Pacific Education Research, 23, (2), 165-177.

Lin, H., \& Hwa,T. (2002). Current research in organizational systems: Higher education. Futuristics, 26, 11-19.

Malik, M., Fatima, G., Abid, H. \& Sarwar, A. (2017) E-learning: Students’ perspectives about asynchronous and synchronous resources at higher education level. 39(2), 183-195.

Niess, M. \& Gillow-Wiles, H. (2013). Developing asynchronous online courses: Key instructional strategies is a social metacognitive constructivist learning trajectory. Journal of Distance Education, 27(1), 1-16.

Peters, L., Shmerling, S. \& Karren, R. (2011). Constructivist pedagogy in asynchronous online education: Examining proactive behavior and the impact on student engagement levels. International Journal on E-Learning 10(3), 311-330.

Pickett, M. (2015). Integrating Complexity and Creativity in Adult Online Learning Environments. Journal of Higher Education Theory and Practice, 15(7).

Sipos, Y., Battisiti, B. \& Grimm, K. (2008). Achieving transformative sustainability learning: Engaging head, hands and heart. International Journal of Sustainability in Higher Education, 9, 68-86.

Svanstrom, M., Lozo-Garcia, F., \& Rowe, D. (2008). Learning outcomes for sustainable development in higher education. International Journal of Sustainability in Higher Education, 9, 339-351.

Vonderwell, S., Liang, X. \& Alderman, K. (2007). Asynchronous discussions and assessment in online learning. Journal of Research on Technology in Education, 39(3), 309-328.

WASC Handbook of Accreditation (2013). [Electronic Version]. Retrieved January 6, 2019, from WASC Accrediting Commission for Senior Colleges and Universities Web site: https://www.wscuc.org/book/export/html/956

Watts, L. (2016). Synchronous and asynchronous communication in distance learning: A review of the literature. Quarterly Review of Distance Education, 17(1), 23032,56. 